\title{
Long Waves and Changes in Socioeconomic Organisation
}

\author{
Carlota Perez
}

The protracted period of stagflation currently experienced by the world economy, coupled with the impotence or short-lived successes of government policies, have made it increasingly difficult to accept single factor explanations such as OPEC oil prices or particular national policies. Instead, interest is growing in a forgotten chapter of economic theory: the occurrence of long - 40-60 year - cycles in economic growth, the so-called Kondratiev long waves.

Although much theoretical debate is still centred around whether their existence can be statistically proven, historical memory is much clearer on the matter. It was commonplace to refer to the late nineteenth century as 'the Great Depression' until the 1930 s made unequivocal claim to that title. The same general agreement seems to fall upon the great prosperities of the "Victorian boom', the 'Belle Epoque' and the promise of unrelenting growth of the 1950 s and early 1960 s.

The reason for such disagreement between social assessment and statistical evidence might lie in expecting long wave phenomena to be a form of behaviour of the economic system, measurable in the same terms as - say - the short business cycles. Consequently, the sceptics insist upon the detection of long cycles in specific economic variables and upon an explanation which would be endogenous to the system. The problem however lies in determining precisely which system it should be endogenous to. Clearly, the economic subsystem can, for many purposes, be treated as self-contained, because of its tremendous amount of internal feedback and selfdetermination. But when it comes to explaining long waves, given the considerable transformations they

\footnotetext{
1 This article is based on a paper presented at the IIASA meeting on 'Long Waves, Depression and Innovation', Siena-Florence, 26-29 October, 1983. For more complete discussions see C. Perez, 'Structural change and the assimilation of new technologies in the economic and social systems", Futures, vol 15 no 5 , October 1983 , pp357-75, and 'Microelectronics, long waves and structural change', forthcoming in World Development.
}

imply in all spheres of society, we need to step out and take a global look at the evolution of the total system. with its technological, social and institutional components interacting with the economic subsystem.

In this article I present a set of hypotheses explaining Kondratiev waves as successive and distinct 'modes of growth' of the total system. Each mode of growth would involve the establishment of a new set of social and institutional arrangements designed to foster the deployment of successive technological revolutions or, as I shall call them, successive "techno-economic paradigms'.

The present period would thus be defined as one of transition from a mode of growth established to accommodate a constellation of technologies based on low-cost oil, to another shaped to suit the requirements of a system of technologies based on low-cost electronics.

\section{Long waves as successive modes of evolution}

Taking this total view, depression in a long wave is a structural crisis. It is not just a halt in economic growth but rather the syndrome of a serious mismatch between the techno-economic subsystem and the socio-institutional framework. In a long wave downswing, we are in fact witnessing the reversal of the positive interaction between these two spheres of the total system.

This implies that what we would actually measure, when detecting long wave behaviour in certain economic variables, would be the impact upon the economy of the increasing degree of 'match", in the upswing, and of 'mismatch', in the downswing. between these two spheres of the system. In other words, depression is the emergency signal calling for full scale reaccommodation of social behaviour and institutions, in order to suit the requirements of a major shift which has already taken place, to a considerable extent, in the techno-economic sphere. 
The upswing, then, can only be unleashed by appropriate social and institutional transformations that will re-establish structural coherence.

But why should this mismatch occur? Mainly because the two sets of subsystems, though in permanent interaction, have very different rates of change. While economic activity, spurred by profit and growth motives, can result in very rapid shifts at the micro level, the additive effect of successive and increasingly massive shifts will only be visible in the aggregate when change has reached critical proportions.

Institutions, on the other hand, not only come late as regards visibility and awareness of these changes, but also suffer from a high degree of 'natural' inertia, strengthened by past successes and upheld by vested interests.

I suggest that the type of fundamental shift which underlies these periods of 'match' and 'mismatch" are successive techno-economic paradigms, diffusing throughout the productive sphere about every 40-60 years. They can be seen as overall technical and managerial revolutions transforming the "how' and the 'what' of profitable production, in general, and establishing a new 'best practice frontier'. Productivity growth under each of these paradigms follows a logistic curve and so does its rate of diffusion across firms, branches and countries.

The upswing in the economy is the steep part of the paradigm curve for both productivity gains and generalisation. It is stimulated by a whole set of social and institutional arrangements, national and international, influencing the operation and evolution of factor and other markets, and designed to suit the requirements of that particular techno-economic paradigm.

As limits to growth are reached along that path, a complex set of interactions between the technological and economic spheres gradually brings about the crystallisation of a new paradigm, which again revolutionises the productive system. Yet the social and institutional mechanisms, adapted to the now 'old' and declining paradigm, cannot cope with the new pattern of investment and the unexpected behaviour of most markets, as the new paradigm diffuses. These mechanisms, therefore, become increasingly powerless and counterproductive. Thus depression is a process of 'creative destruction' not only in the economic sphere but also in the social and institutional.

\section{A techno-economic paradigm}

To avoid misunderstandings, let me make clear that I am not referring just to 'clusters' of technological innovations, but to a system of interrelated product and process, technical, organisational and managerial innovations, embodying a quantum jump in potential productivity for all, or most, of the economy and opening up an unusually wide range of truly new investment and profit opportunities.

Again, when I say 'paradigm' change, I mean a radical transformation in the prevailing engineering and managerial 'common sense' for best productive and most profitable practice. But how would this come about?

The organising principle of each paradigm can be found in the dynamics of the relative cost structure of all possible inputs to production. In it, a particular input (or set of inputs), which could be called the 'key factor' of each paradigm, fulfills, for a relatively long period, the following conditions:

a) clearly perceived low - and descending! - relative cost:

b) apparently unlimited supply (for all practical purposes);

c) obvious potential for all-pervasiveness, and

d) a generally recognised capacity, based on a set of related innovations, to reduce the cost and change the quality of capital equipment, labour and products.

I suggest this conjunction of characteristics holds today for microelectronics, leading the way towards the fifth upswing. It held until recently for oil, which underlay the fourth Kondratiev upturn, together with organic chemicals and other energy intensive materials. Before that, for the third Kondratiev, the role of 'key factor' was played by low-cost steel; for the second, by low-cost coal and steam-powered transportation, and, for the Industrial Revolution or first Kondratiev upswing, one could perhaps argue that the role of "key factor" fell upon low cost machine-tending and cotton-growing labour.

Yet, the new 'key factor' does not appear as an isolated input, but rather as the core of a system of technical and managerial innovations, some related to the production of the key factor itself and others to its utilisation. These innovations take place through an intensive feedback process, spurred by the decreasing capacity of the previous key factor to further diminish costs or increase productivity and profits.

Thus, the corresponding techno-economic paradigm emerges gradually, in the midst of a world dominated by the old, until it clearly appears as the 'ideal type' of productive organisation to take maximum advantage of the particular 'key factor', which is becoming more and more visible in the relative cost structure. The new 
paradigm represents a quantum jump in total factor productivity and opens an unprecedented range of new investment opportunities. It is for these reasons that it brings about a radical shift in engineering and managerial 'common sense' and that it tends to diffuse as rapidly as conditions allow, replacing the investment pattern of the old paradigm.

The full constellation - once crystallised - goes far beyond technical change and brings with it a restructuring of the whole productive system. Among other things, it involves:

a) a new 'best practice' form of organisation at the firm and at the plant level;

b) a new skill profile, affecting both quantity and quality of labour, with its corresponding pattern of income distribution;

c) a new product mix, in the sense that those products which make intensive use of the low-cost key factor will be the preferred choice for investment and will, therefore, represent a growing proportion of GNP;

d) new trends in both basic and incremental innovations geared at substituting relatively high cost elements by more intensive use of the key factor;

e) a new pattern in the location of investment, as the change in the relative cost structure transforms comparative cost advantages;

f) a particular wave of infrastructural investment destined to provide the appropriate externalities;

g) a tendency for the largest firms to concentrate - by growth or diversification - in those branches where the key factor is produced or most intensively used, which results in having distinctly different branches acting as the engines of growth for each Kondratiev upswing.

To give a brief example, the fourth Kondratiev technoeconomic paradigm, now exhausted, was based on low cost oil and energy intensive materials and was led by giant oil, chemicals, automobile and other mass durable goods producers. Its 'ideal type' of productive organisation at the plant level was the continuous flow assembly-line, to turn out massive quantities of identical units (much of it for consumers, which was in itself an innovation, considering that these markets had traditionally been covered by smaller and less productive units, except, of course, in the textile-led first Kondratiev). The 'ideal type' of firm was the 'corporation', with a separate and very complex managerial and administrative hierarchy, including in-house $\mathrm{R} \& \mathrm{D}$ and operating in oligopolistic markets It benefitted from economies of agglomeration and required an everexpanding highway network, together with oil and energy distribution systems for energy intensive production, transportation and lifestyles. It demanded increasing amounts of middle range specialisation in both blue and white collar skills.

Today, with cheap microelectronics widely available (together with the consequent low-cost of information handling), it is no longer 'common sense' to continue along the - now expensive! - path of energy and materials intensity. The 'ideal' productive organisation brings together management and production into one single integrated system (a process we might call 'systemation'), for turning out a flexible output of preferably information-intensive, rapidly changing, products and services. Growth would presumably be led by the electronics and information sectors, requiring massive externalities from an all-encompassing telecommunications infrastructure, which would bring down to negligible the cost of access for producers and consumers alike. The skill profile tends to change from mainly middle range to increasingly high and low range qualifications, and from narrow specialisation to broader and multipurpose basic skills for information handling. Diversity and flexibility at all levels substitute identity and massification as 'common sense' best practice.

\section{Long wave behaviour in growth and techno- economic paradigm shifts}

These merely illustrative examples, sketching some of the main features of two successive techno-economic paradigms, should help to bring to light the amount of innovation that would be required in government and social behaviour to adapt to such shifts in productive practice requirements.

At the micro level, when you introduce numerical control or computer technology in a firm previously working with electromechanical technology, it is not possible to reap all the productivity increase potential without transforming the whole organisation both at the plant and the office levels, including extensive retraining and redefinition of the forms of interaction. In a similar manner, when the full constellation of a new techno-economic paradigm tends to take over the bulk of production with in a society, it will not yield its full growth potential until the socio-institutional framework is transformed to adapt to its requirements.

In the previous upswing, a change as profound as massive state intervention in the economy, along Keynesian principles, was necessary to construct a 'mode of growth' capable of unleashing the full deployment of the oil based paradigm.

Historically, though not always and not only, these changes have affected the specific forms of operation and regulation of the various markets (product, labour, capital, money) on the national and 
international levels; the organisation of the banking and credit systems; the relative proportions and character of public and private responsibility in production, distribution and redistribution of income, as well as the corresponding social arrangements, the forms of organisation of workers and major interest groups, together with the legal framework within which they operate; the social provision of education and training in its quality, volume and the type of institutions in charge of it; the conditions under which inventions are generated, protected and traded; the international division of production as well as the means for regulation of trade and last, but certainly not least, the arrangements for maintaining the international relative power balance.

Clearly, such changes cannot, and indeed have not occurred without social and international conflict, and they are actually the result of a tremendous amount of experimentation. The proposed solutions vary quite widely and, in fact, as far as being able to achieve high rates of growth, they can be as different as fascism and Keynesian democracy, as was seen in the last Kondratiev trough. The challenge, of course, is to strive for appropriate arrangements to achieve both economic growth and maximum social welfare. Yet the outcome will ultimately depend on the relative strength, lucidity and capacity to innovate of the social forces at play.

Let us now briefly look at the four phases of the long wave in the light of techno-economic paradigm changes:

Recovery is the period when favourable social and institutional conditions have been put in place to foster the generalisation of the previously crystallised techno-economic paradigm. Innovations multiply within the range of applications of the paradigm, reaching more and more products, more and more branches and even influencing the form of organisation of non-productive activities. Investment, profit rates and productivity growth are high.

Prosperity is a period of exceptionally high growth rates resulting from the combination of the final optimisation and maximum potential yield of the established and, by then, thoroughly generalised paradigm, and the first successful applications of the future paradigm. The latter generally occur as relatively risky trial and error efforts to avoid diminishing returns on more 'traditional' investment. Other efforts to counter the reduction of profit margins of those reaching the top of the logistic curve may include relocation in search of comparative cost advantages, mergers, acquisitions and whatever forms of speculation are found to be attractive in that particular period.

Recession is the decline of the now 'old' paradigm, aggravated by the cross-currents and counter trends created in most markets by the consequences of the new pattern of investment. This new pattern is created both by the appearance of many new innovative firms and by the efforts at diversification towards the new areas on the part of existing firms. At this time, the first signs of difficulty for further development of the 'new' paradigm are encountered.

Depression is the exhaustion of the 'old' paradigm but with inertia in its corresponding social and institutional mechanisms. The latter have become insurmountable barriers for the fructification of the growth potential of the new techno-economic paradigm and must be transformed.

If the model we have briefly sketched is an acceptable approximation to the workings of the system, its main merit would be to provide a focusing device for orienting social and institutional change in the appropriate direction. It suggests that through a deep understanding of the specific characteristics, requirements, potential and limitations of the constellation of technologies which begins diffusing during a downswing, it is possible to extract criteria for effective social action and policy innovation.

For the social sciences it implies the need for a truly interdisciplinary effort. During upswings it would be possible for each to work within a chosen subsystem with the assumption of 'all other things being equal'. In downswings however, when the interactions are being redefined, the traditional questions might fail to provide the relevant answers. 